\title{
CAN IN-HOUSE TRAINING PROGRAMS REPLACE THE GRADUATE DEGREE? AN EXPLORATION OF DIFFERENCES AND LEARNING OBJECTIVES IN TERMS OF CAREER ADVANCEMENT
}

\author{
Niall Hegarty
}

Niall Hegerty is Assistant Professor in the department of Management at the Tobin College of Business at St. John's University, New York.

\begin{abstract}
This article is a commentary on the (changing) landscape in the education of professional employees. It examines the effectiveness of training programs in terms of learning objectives, as a medium to develop an individual's career, and as a form of recognizable education. Training programs are contrasted with graduate degrees in terms of relevance in meeting organizational demands for a quality workforce and an individual's need for career growth. Main differences between corporate training and formal graduate education are examined as well as alternatives to each in advancing industry knowledge in career development. The article offers recommendations for the improvement
\end{abstract}


of training programs to satisfy both organizational and individual goals.

Keywords:training, careers, in-house, graduate degrees

DOI: http://dx.doi.org/10.15239/j.brcadvje.2014.02.01.ja02

\section{INTRODUCTION}

The fact remains that the world, its people and the processes by which we do business is constantly changing. This means that companies must also change how they do business. They can meet these global changes head on by reacting to them or engage in training to equip employees to handle anticipated future change. How a company chooses to train employees and how employees choose to train themselves is the topic of this article.

At the crossroads of career minded learning for both young and mature professionals lies the decision to either attend a graduate program or further career-focused education through corporate training programs. While organizations seek employees that will improve overall organizational effectiveness, employees for the most part seek to develop their own personal career (Lees, 1992). Consequently, developing a professional career involves choosing a professional training path. The options are numerous and include advanced degrees, professional training programs, in-house training programs, and industry benchmark certificates. With these options come additional considerations such as time investment, monetary cost, and the portability of any newly acquired training. As corporate training programs are often tailored to a specific company or industry niche any newly learned training is intended to directly and positively affect the operations of a company. Such training therefore may lack relevance within companies in the same industry. As a result, company sponsored and paid for training often serves to inadvertently isolate employees from acquiring transferable skills within their industry. 
This article serves to draw attention to the dichotomy of learning between corporate training programs and advanced degrees in satisfying industry knowledge requirements. It seeks to address discrepancies between training and learning in terms of improving human capital. The utopia of meeting organizational needs while also catering to the needs of individual development and achievement continues to remain as the root cause of the multitude of paths available for professional development. While there is a multitude of research on both the value of training programs and the return from a graduate degree, recent years has seen diminished research output. In fact, in an economic climate where organizations are seeking to maximize the returns from training efforts the absence of a body of knowledge comparing these two areas necessitates the need for increased research to act as guidelines for industry.

\section{SURFACE DIFFERENCES}

The main distinction between graduate degrees and corporate training programs is that the degree is considered a credential that serves throughout the course of an individual's career whereas a corporate training program serves the immediate best interest of an organization. Therefore a graduate degree has a focus on developing the individual and providing a collaborative learning environment, whereas a corporate training program is focused on training which provides benefit to the organization in satisfaction of organizational objectives. While an employee may benefit from the learning experience in a training program and also enhance their skills portfolio, it remains that the juxtaposition created is that of individual versus organizational benefit.

Outside of the confines of instruction, a graduate program offers camaraderie, lifetime association, opportunity to interact with others one may not normally interact with, and valuable friendships across disciplines (Jamieson, 2007). In choosing a graduate school one also has the luxury of assessing starting salaries of students from a particular 
graduate school's program. None of the aforementioned are provided by corporate training programs.

An obvious main difference between the two paths of learning is cost to the individual. While in-house training programs come at no cost to the individual an advanced degree brings with it the burden of funding the degree. Although some employers pay a specific amount towards advanced degrees this amount pales in comparison with the overall cost of the degree. The Society for Human Resource Management (2013) reports that $58 \%$ of large employers offer education assistance at the graduate level but only $20 \%$ of employees avail of this benefit. Again, this may be due to the tax free incentive not being large enough to defray a substantial cost of a graduate MBA program.

In terms of content, a graduate degree teaches an individual how to think and how to approach decision making, whereas training programs typically teach a specific skill, or procedure, or are informative in nature.

\section{FACTORS WHICH INFLUENCE CHOICE OF EDUCATION}

Central to bridging the gap between corporate training and formal academic study in a complementary fashion is the tone set by organizational leadership. Management perception of the benefits if each mode of instruction will determine the amount of support provided in either direction. Increased competitiveness between companies means that the quality of the workforce will be the difference. How is that quality best achieved - academically or through in-house training? Regardless, now more than ever countries need a qualified workforce and investment in learning is a requirement. Both avenues of development hold merit. The advanced degree provides both personal satisfaction and prestige while also holding the door open to employment options at other corporations. On the other hand, corporate training programs deliver necessary relevant training to an employee in improving their job performance and gaining recognition from their employer. It also builds an expertise base 
specific to that employer and in some cases a specific industry. Quite often the choice comes down to an individual decision. Factors involved in this decision apart from cost include whether an employee plans on staying with an employer, level of anticipated difficulty of a graduate program, and fear of standardized tests required for admission. In some instances an individual may decide they wish to stay with an employer for the entirety of their career therefore in-house training programs are better suited for increased contribution to overall organization effectiveness.

\section{Choosing the graduate Degree}

Many graduate programs, particularly at private colleges, have experienced challenges in enrollment for a variety of reasons - poor economy, high expense, mass layoffs, and lack of loyalty from organizations. These reasons combined draw attention to the priority given to advanced formal education in developing a career. Furthermore it is difficult to place a monetary value on the return from a master's degree for many to justify the initial expense of enrollment. However, a graduate degree displays an acquired level of thinking ability. The degree essentially is the development of human capital which makes one attractive to perspective employers in that employers feel the attainment of such degrees is indicative of higher productivity returns from individuals.

The added contribution of an MBA has been subjected to scrutiny as it is difficult to quantify the performance results returned by the degree in practice, meaning, if brighter people attend MBA programs and subsequently perform well then it would be reasonable to think that because they are bright they would have performed well anyway without the MBA. The lack of recognized corporate training programs allows master degree programs maintain their attractiveness as a career development vehicle. While some researchers are critical of the value added by MBA programs to the actual practice of management (Mintzberg, 2004; Pfeffer 
\& Fong, 2002) it remains that these programs remain attractive to those seeking to advance corporate careers. Research by Hay (2006) in contrast illustrates that those who pursue an advanced degree realize improved confidence, a solid grounding in theory, and greater overall perspectives. Such returns it would seem benefit not only the individual but also employers of such individuals throughout the course of their working life. Further studies by Hilgert (1995), and Sturges et al (2003) highlight how MBA programs contribute to advance individuals personal development. The emphasis from such research is that although difficult to quantify, those who complete master degree programs report that they feel it contributed to the advancement of their career and personal satisfaction thereby improving their self-efficacy. This aligns with research on Social Learning Theory by Bandura (1982) which informs that individuals observe the performance of others in choosing a directional path and as they embark on a similar path of challenge their self -efficacy grows. An alternative reason may be that because an individual has invested so much time and money into a graduate program they feel compelled to advance themselves to justify attaining the degree and therefore display higher levels of motivation.

MBA programs and all master degree programs put individuals in proximity to similar individuals thereby accommodating the transfer of ideas and opening up new ways of thinking. This goes beyond the hard theoretical and quantitative subject matter of programs and thereby is difficult to measure but nonetheless provides opportunity for learning and development. Therefore the MBA program provides both academic training and exposure to alternative ideas and thought processes which cannot be tested or evaluated but yet linger after the program has been completed.

Hay (2006) posits that MBA programs make an 'indirect contribution to management practice'. This can be explained due to the sharing of ideas and discourse provided by working on team projects during the pursuit of the MBA degree. 


\section{ChOOSING CORPORATE TRAINING}

While all will agree that education is a commonly accepted vessel of advancement the cost of such advanced training has made the master degree route prohibitive for many. This has resulted in more attendees at company sponsored training and as such has necessitated corporate training programs to improve not only the delivery of such programs but also the quality of the material being presented. Corporate training, both in-house and from recognized training companies is now at an advanced stage where training can be tailored for a specific group of employees. Such directed training focuses on direct organizational needs and equips the employee to satisfy market changes demanded of personnel while also providing an element of job security. However, variance in quality of training programs, lack of consistency, and difficulty in measuring outcomes continues to hamper portability and makes such programs difficult to include on a resume.

Although quantifying training returns is often hard (Owens, 2006; Chochard \& Davoine, 2011) employees that engage training programs report higher job satisfaction, greater organizational commitment, and are less likely to leave a company. While all organizations readily voice support of training employees such training will only become effective upon completion of an accurate needs assessment which will determine the type of training to be delivered. Tannenbaum and Yukl (1992) have emphasized the necessity for organizational analysis in terms of training development. Their research also notes the need for pre and post testing when training is delivered. These authors feel that such testing is a necessity with an emphasis on training that gets absorbed and manifests at the behavioral and results level which directly impact organizational improvement. As these analyses are therefore responsible for any training programs designed it is vital that any needs analysis conducted is done so correctly. More so than laud and support corporate training programs, various industries would be better served by high level development of standardized training programs that require minimal manip- 
ulation for individual company application. If such foundational work is done then benchmark training programs can be identified which would solidify external parties core understanding of training received. Until such recognizable benchmarks in training delivery exist then any training delivered, regardless of quality, will retain only internal company value. Individuals must therefore be aware that attendance of corporate training programs may not return career growth options outside of their current employer, and enrollment in such programs should not be done with the view to building one's attractiveness to other employers.

Another vein in the corporate training is that of leadership development programs. These programs are typically populated by executive track employees (Morrison, 2012) and can often take up to two years to complete as in the case of GE's Human Resource leadership Program, IBM's Leadership Development Program, and Chrysler's Leadership Development Program (LDP). These exclusive programs are very well regarded as learning platforms, however, they typically favor candidates who have already acquired an MBA for consideration and therefore can be considered to be 'next-generation' in terms of advanced corporate learning. Development programs it should be noted, however, differ from training programs in that they have a long term strategic goal in cultivating employees to ensure the long term survival of a company whereas training is considered to be more on a short term, immediate implementation timeline (Yeh \& Pin, 2011; Stevenson, 2012). In addition, the existence of corporate universities at companies such as Deloittte and Lufthansa adds another layer in specialized training where employees are immersed in training to acquire skills to directly impact organizational operations (Brown, Hassan, \& Teare, 2011; Gilbert, 2013; Sinha \& Kaul, 2013). 


\section{Challenges facing training PROGRams}

While corporate training programs provide valuable information to employees they face numerous challenges both in terms of content and credibility. One such challenge facing corporate training programs is that training directors are not normally part of the overall company planning committee (Kalman, 2008). This shows that while corporate executives realize the value of training employees they do not consider those responsible for workforce training to be included in organizational strategy development. For training programs to gain credibility it remains that their value must be recognized by senior management and counsel sought from those responsible for training as to industry direction in terms of skill development in order to remain competitive. This would then not only reflect an organizational commitment to growing talent but also force training departments to directly address organizational needs in an accountable fashion.

Is there a dynamic shift in the education of professional workers? Who places value on graduate degrees? While corporations may claim they can teach employees in-house, when interviewing they may naturally gravitate to the credentialed candidate as they feel such an individual has the wherewithal and work ethic desired. Consequently, it may be argued that corporations engage in expensive self-defeating behavior by preferring advanced degrees over training programs when recruiting. McDonald and Hite (2008) report lack of further education as a perceived barrier to career success within companies due to employers preferring new hires with master degrees. While this may not be true in all cases such perceptions exist which staunch career development. Furthermore, research by Bidwell (2011) states that outside hires earn as much as $18 \%$ more than internally promoted employees and bring with them higher levels of experience and education.

Another issue is the notion by Antonacopoulou (2001) that training may not always result in learning. This introduces the concept that training is of benefit to particular operational functions whereas the 


\section{BRC Journal of Advances in Education Vol. 2, No. 1}

art of learning can be drawn upon and used when necessary in future situations. Learning creates the understanding of fundamental concepts that can be modified and applied to different scenarios whereas training appears to be function and situation specific. This therefore bodes the question as to whether organizations are willing to make the long term investment in their employees, and how much creativity is valued in problem solving. Consequently, the value of management training is dominant in such decision making.

For clarification purposes training is normally for operational levels where a specific skill is acquired, whereas learning seems to be associated with the higher decision making managerial levels. This therefore bodes the question of organizational commitment to growing talent internally and providing advanced learning to individuals in the form of graduate degrees such as MBA's which in a cohort fashion can be tailored to an employer's needs. As this does not seem to be a preferred avenue for employers it prompts discussion on how committed management is to growing the next crop of internal leaders.

An indirect result of training is that it makes employees happier in their jobs and more committed to the organization (Hardre \& Reeve, 2009). Employees also feel that their organization is committed to them. In terms of promoting morale should this be an actual goal of training as opposed to looking for real results from training? Consequently it questions organizations' reasons for training. Training programs therefore may be nothing more, in some cases, than making employees feel greater job satisfaction. While this researcher readily accepts that there is no monetary value that can be placed on the return from a satisfied and dedicated employee, training programs as a method to achieve that job satisfaction remains very questionable.

Also, training may simply be used as a tool to alleviate fears of employees with regard to impending changes. As opposed to learning, this author believes in the merit of training programs in such instances 
as it serves to make employees more effective in the future which is the purpose of training within the realm of organizational development.

\section{FrAMiNg LEARNing OBJECTIVES}

While training increases the likelihood an employee may leave a company it also increases employee commitment. But this is contingent upon the education level and position level within a company. Hansson (2007) suggests that economic return from training outweighs the costs of employee turnover as a result of training. Staff turnover as a result of training may be because training received in a specific area of expertise is valued by another company, such as in the area of information systems, or training that helps achieve an industry recognized certification. Barrett and O'Connell (2001) support the view that companies gain more from general than specific training. This subsequently supports the position that general training benefits the company whereas specific training benefits the individual employee. However, what remains constant is that both needs must be met in developing training program objectives.

Firms that promote more from within invest less in training (Hansson, 2007). Hansson also states that the major factor affecting the type and level of training depends on company management. This suggests that senior level commitment to training and development as part of organizational values and mission is tantamount to the priority level training is given. Senior management that promote from within therefore could utilize training programs as a form company indoctrination and talent development.

Industry-wide, until training is seen as a key ingredient to competitive advantage it runs the risk of merely existing as lip service to executives claiming to value employees. Consequently, training programs need specific learning goals which must be measurable. 


\section{BRC Journal of Advances in Education Vol. 2, No. 1}

Already mentioned, a challenge facing the credibility of training programs is the availability of certification examinations in specific niche areas. These certification examinations have specific learning goals which training programs lack. And while companies recognize the value of such qualifications oftentimes the employee still lacks the hands-on training that makes them more effective in their position for a company. Filling in such gaps is where the strength of training programs lie. And if such gaps are generally industry-wide then a tailored made industry recognized training program is an avenue for creating credibility for portable corporate training programs. Corporate training programs need uniformity as they are normally designed for a specific company and for this reason recognition of skills acquired in training programs becomes difficult to identify as opposed to an earned master's degree from an accredited university. Thus, training programs as a vehicle of career development lack the credibility and recognition afforded a graduate degree. To encourage the development of learning goals companies may need to consider incorporating a training policy. Such learning policies have already been adopted by the federal government as a learning development tool (Clardy, 2008). However, to achieve this, human resource executives must be included in strategy development in order to create mission-centered and results-oriented training.

Training may also simply apply to rote processing of new procedures. Learning, consequently uses training to effect gradual change which gets incorporated into the employees portfolio of competencies. It is also important to understand the subtle differences between learning and development. For job specific functions which are in the process of change learning is provided to inform the employee of new procedures. With a more long term outlook organizations engage development to improve future effectiveness. In development the employee holds partial responsibility for taking decisions to improve their skill set and enhancing their career with the goal of realizing greater rewards in the future. Depending on specific employee requirements organizations 
must decide whether to train employees or develop them (McDowall \& Saunders, 2010; Antonacopoulou, 2001).

Asplund (2005) states that company provided training benefits the employer more than the employee which suggests corporate training programs do not provide for the career of the employee. And while changing employer can be a method to raise income as one gains skills (Reitman \& Schneer, 2005) the fact remains that $42 \%$ of laid-off workers find employment in other industries while a further $40 \%$ change job function (O’Brien, 2013). This would seem counterproductive to changing employers once skills have been acquired from training programs for the purpose of increasing one's salary. Consequently training programs need to impart to employees knowledge that is of service to their career development should they stay or leave an employer. This needs to be communicated to the employee to encourage a more vested approach to learning and development.

Training has two goals - overall organizational effectiveness and improving individual performance. With these in mind many questions need to be addressed in determining whether goals have been met: Should training be tied to profitability? Does training drive profit or profit drive training? How do you measure? Timeframe? Hansson states that globally those companies who invest in training realize gains from it. Indeed, organizations with a commitment to quality improvement who pursue International Standards for Standardization (ISO) certification invest heavily in training (Quazi \& Jacobs, 2004). This therefore implies that organizations who invest in training do so as part of an overall corporate strategy. However, some companies who would like to invest in training simply do not have the financial capacity to do so. This can in effect produce a stagnation of organizational development as a company struggles to maintain viability. Thus, this creates a spiraling effect in terms of employee skill levels in the face of highly profitable competitors. Also, as outlined by Goergen, Brewster, and Wood (2009) 
the heightened level of immediate competition a company faces forces companies to focus on the short term.

Once an organization decides to commit to funding graduate school it must demand returns from employees. The higher cost of graduate school is such that the knowledge imparted must be cutting edge to give students an advantage and the quality of teaching must be such that students are excited by the subject matter being presented. In other words, due to cost, graduate schools must be more accountable for both the quality of content, and teaching if they are to satisfy the returns demanded by industry.

\section{HOW MUCH TRAINING IS NEEDED AND WHO SHOULD BE TRAINED?}

Central to training programs is their required purpose. For example, a re-organization may require training in the areas of new processes and computer systems. And while these are specific training programs with start and end dates and a required performance output upon completion, most training programs lack such focus that directly impacts work performance in a quantifiable way. Therein lies the conundrum faced by program developers and providers - how much training to provide over a specific period and how to confirm the impact of training. The lack of parameters in this area has given rise to certification exams which are recognizable, quantifiable, and cost effective to both individuals and employers. These exams quite often require the employee to self teach and acquire qualifications which are of benefit to an employer. The cost of these qualifying examinations are sometimes but not always funded by an employer. Regardless, the employer is realizing a tremendous gain in human capital. Qualifying examinations are numerous and industry specific. For clarification purposes such examinations include the CPA, CMA, and CFA in the areas of finance and accounting, the IE and PE in the engineering field, and the PHR and SPHR in human resources. 
According to Training magazine's 2013 industry report, expenditures on training fell slightly in 2013 to $\$ 55.4$ billion from $\$ 55.8$ billion in 2012 which suggests a leveling off in spending from 2011's $\$ 59$ billion (http:// www.trainingmag.com/content/2013-training-industry-report). Despite a drop in spending such immense figures would seem to indicate that subsequent performance measures must in place to justify such spending. However, this researcher has not discovered accountability for results one would assume would be attached to such spending.

The same report states that company employees spend approximately 37.5 hours a year in training and that the average 2013 spend per employee in the United States was $\$ 881$. Although this is just an average for all workers is seems improbable that worthwhile learning is taking place unless these expenditures are heavily concentrated on certain individuals, essentially meaning that not all workers are getting trained.

Also of interest, tuition reimbursement above $\$ 5,250$ is considered to be income for individual tax reporting purposes. For many, this may be a deterrent in pursuing the degree. However, any tuition paid by an organization can be written off as an expense which would seem to suggest that it is in the best interest of an organization to encourage it's employees to further their education in their professional field. Of course, companies operating on a tight budget may not be in a position to fund this short term expense on a company-wide scale. Consequently, what appears to be trending in the training industry is that because the skills required are very niche, training programs are becoming very company and position focused which is spurring on specialized in-house training.

Degree programs offered by universities which tailor some classes directly to the need of the organization without compromising the integrity of the degree would provide excellent training to employees which would be of benefit to an organization while also satisfying the individuals need for personal development. Such a model speaks directly to both constituencies. With a semester long course exceeding 40 hours 
a single course alone consumes the same amount of time as an employee receives in corporate training in a whole year. However, the cost associated with such education is quite substantial and normally is only directed toward employees on the managerial track.

While companies prefer classroom type training their expenditures for it appear contingent upon specific company related performance. In other words while the traditional classroom approach is recognized as the preferred form of training companies are not prepared to pay for a degree which speaks to career long skills as this training may or may not benefit the company in the long run. Specifically, companies remain only interested in training that is of productive benefit to the organization without consideration of employees' individual career goals (Ballot, Fakhfakh, \& Taymaz, 2006). And while they are not obligated to be responsible for the career development of individuals, a happy medium should be sought in order to enhance employee commitment, effectiveness, and workplace harmony. The outlook of any company is directly related to the outlook the employees hold for themselves within that company.

In house training is particularly good for operations and manufacturing positions which involve repetition but returns are harder to measure in terms of leadership and executive positions which involve more interactions with peers. And the challenge with in-house training at the executive level is the lack of willingness of senior executives to groom or mentor successors beyond training sessions. This can be due to a combination of time constraints and location of subordinates. In such cases individuals on the cusp of higher decision making may be better advised to enroll in an MBA program which advocates collaborative learning that can serve as a method to accelerate organizational development (Baldwin, Bedell, \& Johnson, 1997). Furthermore, Watland, Hallenbeck and Kresse (2008) advocate that MBA programs should provide more peer communication and feedback to effect more positive organizational change. 


\section{Alternatives to training programs}

Although a graduate program is the obvious alternative to corporate training, in cases where such a commitment is not possible other alternatives must be explored. As stated earlier, industry recognizable certification is a viable alternative to gain the knowledge and credibility to advance an individual's career. Building upon such credentials an individual may also opt to heavily attend industry conferences and trade fairs to build one's 'stock' as an expert and thereby open opportunities for job offers. Along this vein, speaking as an expert at trade fairs will also help expose one to the best practices and minds within an industry. Furthermore, publications in trade journals help bolster one's knowledge base and exposure. This acquired knowledge can then be used to enhance in-house training programs to ensure they are consistent with industry developments. From the outset this researcher sought to explore the possibility of in-house training programs as a viable alternative to a graduate degree. The take-away is that while corporate training programs cannot replace a graduate degree they can enhance the competitiveness of an employee if used in conjunction with these other methods of career advancement.

\section{Discussion AND CONCLUSION}

This article sought to explore the purpose of training programs in advancing employee knowledge as opposed to the pursuit of a graduate degree. The lack of research in comparing outcomes from training programs across a variety of companies makes empirical research into this area difficult. The obvious difficulty in securing such information makes this topic both interesting and obscure thereby rendering any conclusions drawn as speculative. However, the relevant discoveries unearthed highlight the juxtaposition of organizational goals and employee goals in attending training programs. Training programs in their present format serve the needs of employers without immediate 
regard for assisting employees shape their career. They currently do not provide any way to address the satisfaction of organizational and individual objectives. This author advocates the development of training programs that also address the needs of employees. Furthermore, the return on training programs needs to be quantified. The immense size of the training industry without being required to return specific results seems out of step with the operation of all modern organizations.

The need for clearly defined learning objectives, measurable results, and recognizable training programs are vital for the justification of investment in training. Until such time as the industry embraces such requirements in return for their monetary investment it is difficult to see how training programs will remain anything other than 'workshops'.

To truly commit to training and the development of new leaders corporations may be better advised to pay for graduate programs for long term employees at the mid manager level. Graduate programs require the attainment of certain standards, and course projects can easily be tailored to an individual's professional career interests. Although expensive, the employee is exposed to learning and thinking structures which will aid in decision making as one's career progresses. Also, for long term employees, employer funding endorses commitment to the individual and encourages an employee to commit their future to a company. Regardless, commitment to and from the employee appears to hold the solution in improving the landscape of company sponsored training, be it in graduate school or in house training.

\section{REFERENCES}

Asplund, R. (2005). The provision and effects of company training, Nordic Journal of Political Economy, 31, 47-73.

Antonacopoulou, E. (2001). The paradoxical nature of the relationship between training and learning, Journal of Management Studies, 38(3), 327-350. http://dx.doi.org/10.1111/1467-6486.00239 
Baldwin, T., Bedell, M., \& Johnson, J (1997). The social fabric of a team based MBA program: Network effects on student satisfaction and performance, Academy of Management Journal, 40(6), 1369 -1397. http://dx.doi.org/10.2307/257037

Ballot, G., Fakhfakh, F., \& Taymaz, E. (2006). Who benefits from training and R\&D, the firm or the workers? British Journal of Industrial Relations, 44(3),473-495. http://dx.doi.org/10.1111/j.1467-8543.2006. 00509.x

Bandura, A. (1982). Self-efficacy mechanisms in human behavior. American Psychologist, 37, 122-47. http://dx.doi.org/10.1037/0003-0 66X.37.2.122

Barrett,A., \& O'Connell, P.(2001). Does training generally work? The returns to in-company training. Industrial and Labor Relations Review, 54(3), 647-662. http://dx.doi.org/10.2307/2695995

Bidwell, M. (2011). Paying more to get less: The effects of external hiring versus internal mobility, Administrative Science Quarterly, 56(3), 369-407. http://dx.doi.org/10.1177/0001839211433562

Brown, P., Hassan, S., Teare, R. (2011) Sandals Corporate University: the change-included experience, Worldwide Hospitality and Tourism Themes, 3(1), 71 - 77. ttp://dx.doi.org/10.1108/17554211111104970

Clardy, A. (2008). Policies for managing and training and development function: lessons from the federal government, Public Personnel Management, 37(1), 27-54.

Chochard, Y., \& Davoine, E. (2011). Variables influencing the return on investment in management training programs: a utility analysis of 10 Swiss cases. International Journal Of Training \& Development, 15(3), 225-243. http://dx.doi.org/10.1111/j.1468-2419.2011.00379.x

Gilbert, D. (2013) The generation of public intellectuals, corporate universities, graduate employees, and the labor movement, Labor Studies Journal, 38(1), 32-46. http://dx.doi.org/10.1177/0160449X134 90407

Goergen, M., Brewster, C., \& Wood, G. (2009). Coorporate governance and training, Journal of Industrial Relations, 51(4), 459-487. http://dx. doi.org/10.1177/0022185609339513 
Hansson, B. (2007). Company based determinants of training and the impact of training on company performance, Personnel Review, 36(2), 311-331. http://dx.doi.org/10.1108/00483480710726163

Hardre, P., \& Reeve, J. (2009). Training corporate managers to adopt a more autonomy-supportive motivational style towards employees, and intervention study, International Journal of Training and Development, 13(3), 165-184. http://dx.doi.org/10.1111/j.1468-2419.2 009.00325.x

Hay, A. (2006). Seeing differently: putting MBA learning into practice. International Journal of Training and Development, 10(4), 291-297. http://dx.doi.org/10.1111/j.1468-2419.2006.00262.x

Hilgert, A. D. (1995). Developmental outcomes of an executive MBA programme, fournal of Management Development, 14(10), 64-76. http:// dx.doi.org/10.1108/02621719510100843

Jamieson, A. (2007). Higher education study later in life: what is the point? Ageing and Society, 2793), 363-384.

Kalman, H. (2008). Transforming the corporate training program through developing and training strategy and advisory board, Performance Improvement Quarterly, 20(3/4), 75-94. http://dx.doi.org/10.1002/piq. 20004

Lees, S. (1992). Ten faces of management development, Management Education and Development, 23(2), 89-105.

McDonald, K., \& Hite, L. (2008). The next generation for career success: Implications for HRD, Advances in Developing Human Resources, 10(1), 86-103. http://dx.doi.org/10.1177/1523422307310116

McDowall, A., \& Saunders, M. (2010). UK managers' conceptions of employee training and development, fournal of European Industrial Training, 34(7), 609-630. http://dx.doi.org/10.1108/03090591011070752

Mintzberg, H. (2004). Managers not MBA's. A Hard Look at the Soft Practice of Managing and Management Development (Harlow, UK: Pearson).

O’Brien, M. (2013, March). Facts and figures: Switching industries, $H u^{-}$ man Resource Executive, 58. 
Owens, P. (2006). One more reason not to cut your training budget: the relationship between training and organizational outcomes, Public Personnel Management, 35(2), 163-171.

Pfeffer, J., \& Fong, C. (2002). The end of business schools? Less success than meets the eye, Academy of Management Learning and Education, 1, 78-95. http://dx.doi.org/10.5465/AMLE.2002.7373679

Quazi, H., \& Jacobs, R. (2004). Impact of ISO 9000 on training and development activities: An exploratory study. The International fournal of Quality and Reliability Management, 21(4/5), 497-517. http://dx.doi. org/10.1108/02656710410536545

Reitman, F., \& Schneer J. (2005). The long term negative impacts of managerial career interruptions, Group \& Organization Management, 30(3), 243-262. http://dx.doi.org/10.1177/1059601104269110

Sinha, A., Kaul, N. (2013). Glorified training departments or more? fournal of Resources Development and Management, 1, 49-53.

Society for Human Resource management (2013). Designing and managing educational assistance programs. Retrieved from http://www.shrm.org/templatestools/toolkits/pages/ educationalassistanceprograms.aspx

Stevenson, B. (2012). Developing an awareness and understanding of self-organization as it relates to organizational development and leadership issues. Emergence : Complexity and Organization, 14(2), 69-85.

Sturges, J., Simpson, R., \& Altman, Y. (2003). Capitalising on learning: an exploration of the MBA as a vehicle for developing career opportunities, International Journal of Training and Development, 79(1), 53-56. http://dx.doi.org/10.1111/1468-2419.00170

Tannenbaum, S., \& Yukl, G. (1992). Training and development in Work organizations, Annual Review of Psychology, 43, 399-441. http://dx. doi.org/10.1146/annurev.ps.43.020192.002151

Training Magazine (2013). 2013 Training Industry Report. Retrieved from http://www.trainingmag.com/content/2013-training-industry-report.

Watland, K., Hallenbeck, S., \& Kresse, W. (2008). Breaking bread and breaking boundaries: a case study on increasing organizational 


\section{BRC Journal of Advances in Education Vol. 2, No. 1}

learning opportunities and fostering communities of practice through sharing meals in an academic program, Performance Improvement Quaterly, 20(3/4), 167-177. http://dx.doi.org/10.1002/piq.20009

Yeh, Q., \& Fang, P. (2011). A resource-based analysis of organizational turnaround: The contingency role of organizational life stages. Journal of Management and Organization, 17(6), 782-796. http://dx.doi.org/ 10.5172/jmo.2011.17.6.782

\section{Citation Information}

Hegarty, Niall. "An Exploration of Differences and Learning Objectives in Terms of Career Advancement." BRC fournal of Advances in Education 2, no. 1 (2014): 13-34. http://dx.doi.org/10.15239/ j.brcadvje.2014.02.01.ja02 